\title{
How We Teach: Thermodynamics
}

\section{Dr. Margot A Vigeant, Bucknell University}

Margot Vigeant is a professor of chemical engineering at Bucknell University. She earned her B.S. in chemical engineering from Cornell University, and her M.S. and Ph.D., also in chemical engineering, from the University of Virginia. Her primary research focus is on engineering pedagogy at the undergraduate level. She is particularly interested in the teaching and learning of concepts related to thermodynamics. She is also interested in active, collaborative, and problem-based learning, and in the ways hands-on activities such as making, technology, and games can be used to improve student engagement.

\section{Dr. Jennifer Cole, Northwestern University}

Jennifer Cole is the Assistant Chair in Chemical and Biological Engineering in the Robert R. McCormick School of Engineering and Applied Science at Northwestern University and the Associate Director of the Northwestern Center for Engineering Education Research. Dr. Cole's primary teaching is in capstone and freshman design, and her research interest are in engineering design education.

\section{Dr. Kevin D. Dahm, Rowan University}

Kevin Dahm is a Professor of Chemical Engineering at Rowan University. He earned his BS from Worcester Polytechnic Institute (92) and his PhD from Massachusetts Institute of Technology (98). He has published two books, "Fundamentals of Chemical Engineering Thermodynamics" and "Interpreting Diffuse Reflectance and Transmittance." He has also published papers on effective use of simulation in engineering, teaching design and engineering economics, and assessment of student learning.

\section{Dr. Laura P. Ford, University of Tulsa}

LAURA P. FORD is an Associate Professor of Chemical Engineering at the University of Tulsa. She teaches engineering science thermodynamics, mass transfer/separations, and chemical engineering senior labs. She is a co-advisor for TU's student chapter of Engineers Without Borders USA. Her email address is laura-ford@utulsa.edu.

\section{Dr. Lucas James Landherr, Northeastern University}

Dr. Lucas Landherr is an associate teaching professor in the Department of Chemical Engineering at Northeastern University, conducting research in comics and engineering education.

\section{Dr. David L. Silverstein P.E., University of Kentucky}

David L. Silverstein is a Professor of Chemical Engineering at the University of Kentucky. He is also the Director of the College of Engineering's Extended Campus Programs in Paducah, Kentucky, where he has taught for 19 years. His PhD and MS studies in ChE were completed at Vanderbilt University, and his BSChE at the University of Alabama. Silverstein's research interests include conceptual learning tools and training, and he has particular interests in faculty development. He is the recipient of several ASEE awards, including the Fahein award for young faculty teaching and educational scholarship, the Corcoran award for best article in the journal Chemical Engineering Education (twice), and the Martin award for best paper in the ChE Division at the ASEE Annual Meeting.

\section{Dr. Christy Wheeler West, University of South Alabama}




\section{How We Teach: Thermodynamics}

\section{Introduction}

The AIChE Education Division Survey Committee is a volunteer group that seeks to compile, analyze, and broadly share timely and comprehensive information with the chemical engineering community on the content, pedagogy, and implementation of undergraduate chemical engineering courses and curricula. Through this, we hope to enable more informed course and curriculum design throughout the chemical engineering community. The 2018 survey focused on "Thermodynamics," a core engineering science. Thermodynamics is perhaps the topic from the chemical engineering core with the best available prior documentation, having been treated by the AIChE Survey Committee in 1973, 1976, 1982, and 1992 (1-4), and having been studied at some depth by an international group lead by Ahlstrom in 2010 (5).

\section{Methods}

The survey contained 40 mostly multiple-choice questions about undergraduate thermodynamics instruction. An electronic copy of the survey questions is available from the corresponding author upon request. Invitation links to the online survey were distributed via email to all US Chemical Engineering Department Chairs, to all ASEE Chemical Engineering Division and AIChE Education Division members, and through social media. 86 substantially complete responses were collected, from 83 US institutions and three international institutions. Responses were collected between September 10, 2018 and December 5, 2018.

\section{Results}

\section{Courses, Credits, and Demographics}

The responding programs display a near-representative sample of US Chemical Engineering programs in terms of student and faculty size (Figure 1). As noted in the Curriculum survey (6), the past decade has been one of growth for undergraduate chemical engineering programs. 


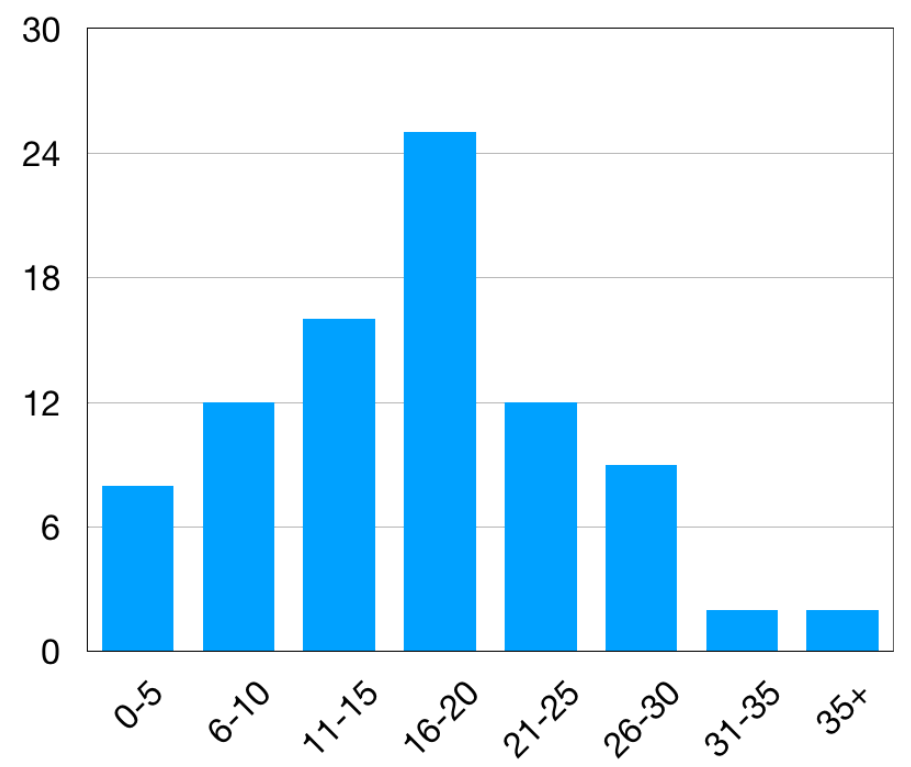

Figure 1: Faculty size, including all instructional faculty (2018)

While the overall number of students in chemical engineering has grown, the most typical size for a thermodynamics course remains about 50 students, with multiple sections becoming common for larger programs (Figure 2).

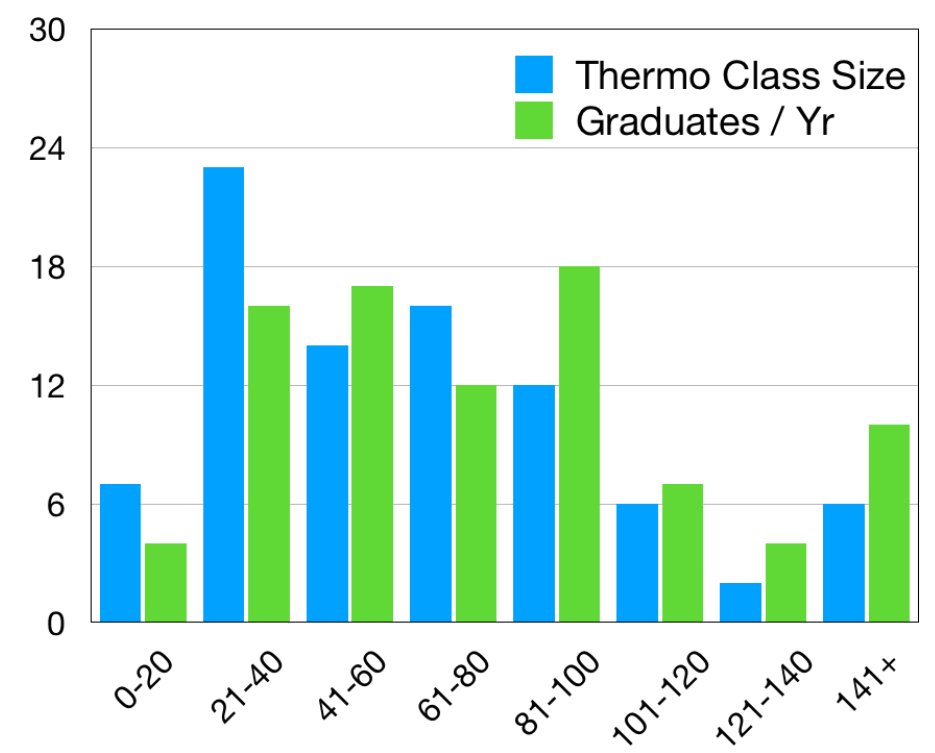

Figure 2: Class size for thermodynamics courses and overall graduating class size.

Within the survey, the following definitions were employed to distinguish the different courses with thermodynamics content. They are presented as they appeared in the survey.

Physical Chemistry course: A course typically taught by the chemistry department. This course may have chemistry majors as the primary audience. Often, this is offered as a two-course sequence, where the chemical engineering majors take either one or both 
semesters.

General Thermodynamics course: A course typically taught within the engineering college/program. This course may be taught as a general engineering course and taken by many engineering majors, such as mechanical, civil, and chemical. This course often centers on the first and second laws and cycles.

Chemical Engineering Thermodynamics course: A course in thermodynamics typically taught within chemical engineering to a primary audience of chemical engineers. Such a course typically includes equations of state, activity models, and other approaches to modeling fluid behavior, as well as reaction thermodynamics. Most departments offer one or two required courses of this nature. While we will ask about the presence of the other courses in your curriculum, our topical questions are primarily focused on courses of this type.

The most common model for chemical engineering curricula is one course in physical chemistry and one course in chemical engineering thermodynamics (Figure 3). Nearly as popular is no course in physical chemistry and two courses in chemical engineering thermodynamics. While it was relatively common in the past (see Discussion), curricula have moved away from a course in general thermodynamics plus a chemical engineering course (only one reporting program) towards two exclusively chemical engineering courses. Nine programs $(10.7 \%)$ reported a single thermodynamics course, with one of those $(1.2 \%)$ offering the course as a physical chemistry course rather than as a chemical engineering course.

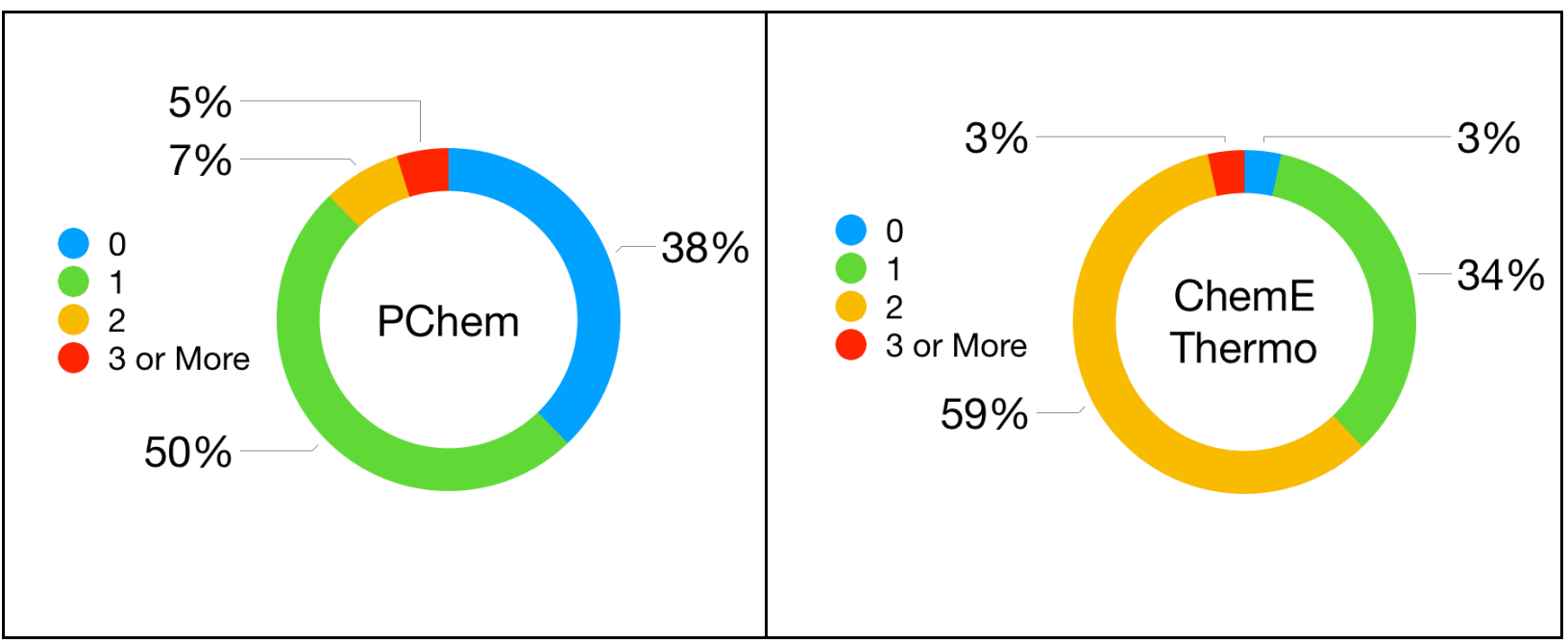

Figure 3: Number of Physical Chemistry (PChem) and Chemical Engineering Thermodynamics courses required, by $\%$ of reporting programs.

$70 \%$ of programs teach their first thermodynamics course in the sophomore year. For the departments requiring physical chemistry, $62 \%$ of them require the course in the junior year. The plurality of programs (48\%) teach thermodynamics as a 3.0 credit-hour course or equivalent, while nearly a quarter $(23.5 \%)$ teach a 4.0 or 4.5 credit-hour course. 


\section{Content}

Of the 84 institutions that responded to the survey, 62 used only one main textbook with their course sequence. Another 18 institutions used a combination of two textbooks, and four institutions used a combination of three textbooks or more. Of the 62 institutions using only one textbook, 47 percent continue to use Smith, van Ness, Abbott, and Swihart as their textbook; this textbook has been the most popular chemical engineering thermodynamics textbook since at least 1973 (1). Texts by Elliot and Lira, Dahm and Visco, and Koretsky were used by 14.5 percent, 12.9 percent, and 11.3 percent of institutions, respectively. When accounting for all institutions, Smith, van Ness, Abbott, and Swihart was the most popular overall book to use, being used by 52.4 percent of institutions. Sandler was the second most popular textbook overall at 16.7 percent.

With respect to the textbook format, 81 of 84 institutions make use of a physical paper textbook, while 56 of the 84 either also or instead use a e-book of the textbook.

Questions were included in the survey on the topics covered within physical chemistry and thermodynamics courses. Figures $4-7$ show typical coverage distribution of topics. There is broad coverage of the first and second laws, their application to unit operations and cycles, and equations of state, each of which is addressed by well over half of all programs in their first (or only) course. Multi-component equilibria, fugacity, chemical potential, activity models, partial molar properties, and reactions are also covered by the vast majority of programs, but they are split between the first (or only) thermodynamics course and the second. The remainder of topics are covered by less than half of all programs.

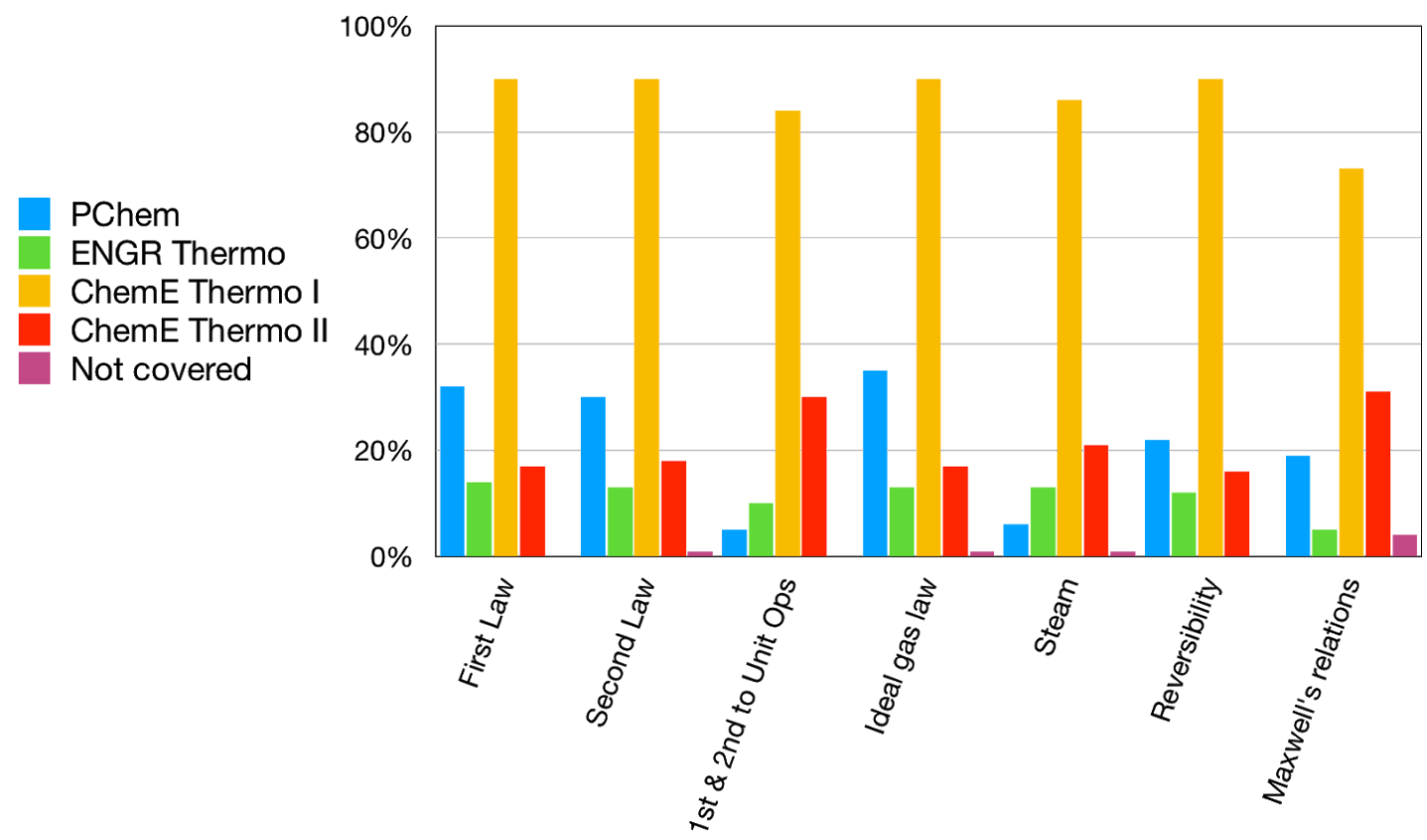

Figure 4: Distribution of thermodynamics fundamentals between courses. Topics may be reported to appear in multiple courses. 
While energy balances are clearly addressed in nearly every course (Figure 4), in only $13 \%$ of courses was this the students' first experience using energy balances. In general, students have taken a mass and energy balances class earlier that may be their first introduction to rigorous application of the concept of conservation of energy.

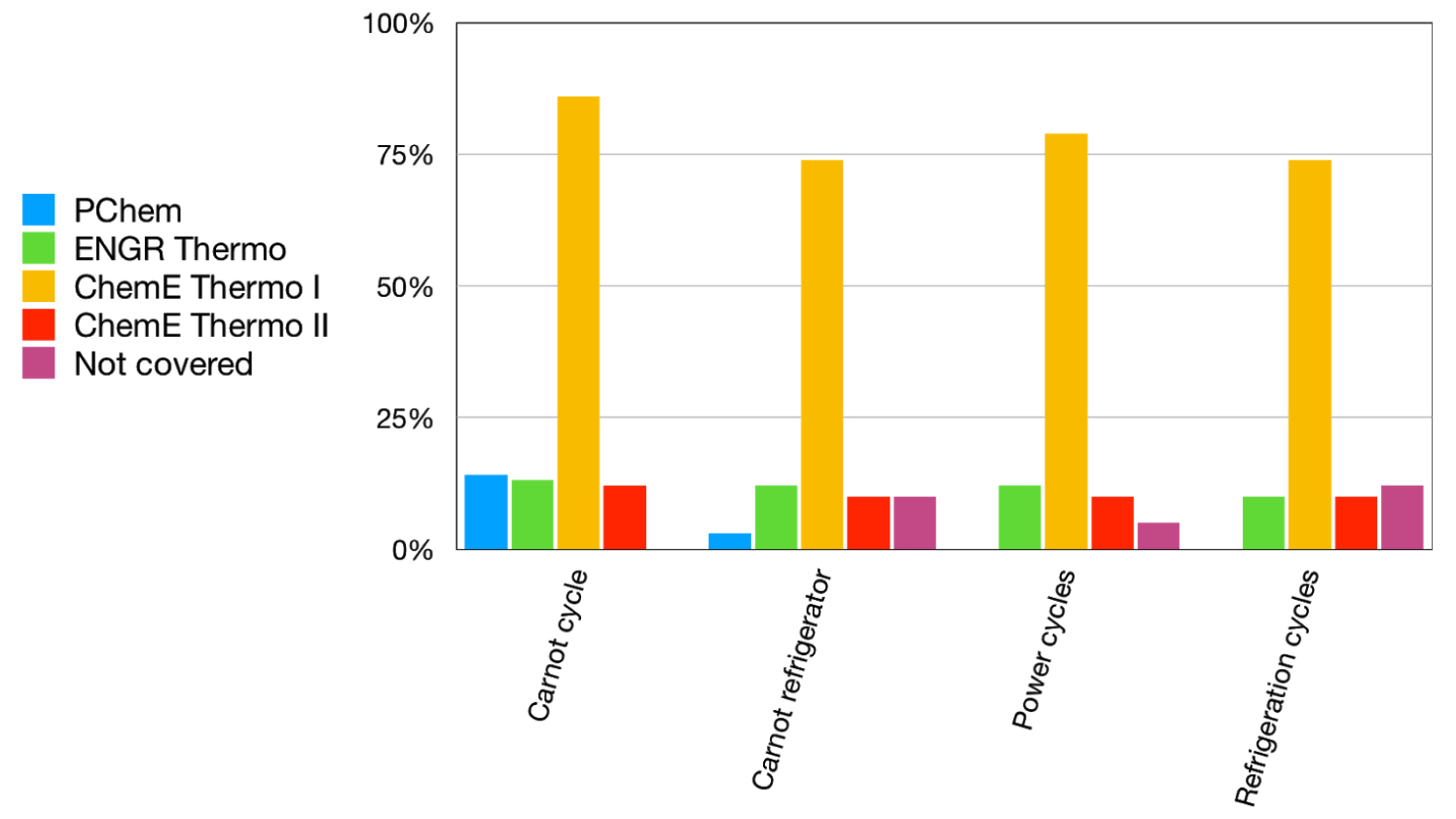

Figure 5: Cycle coverage in courses. Topics may be reported to appear in multiple courses.

While most programs reported covering thermodynamic cycles, most reported discussing only one power or refrigeration cycle in addition to Carnot engines and refrigerators. The most popular of these were the Rankine cycle (57 programs) and ordinary vapor compression refrigeration (37 programs). 


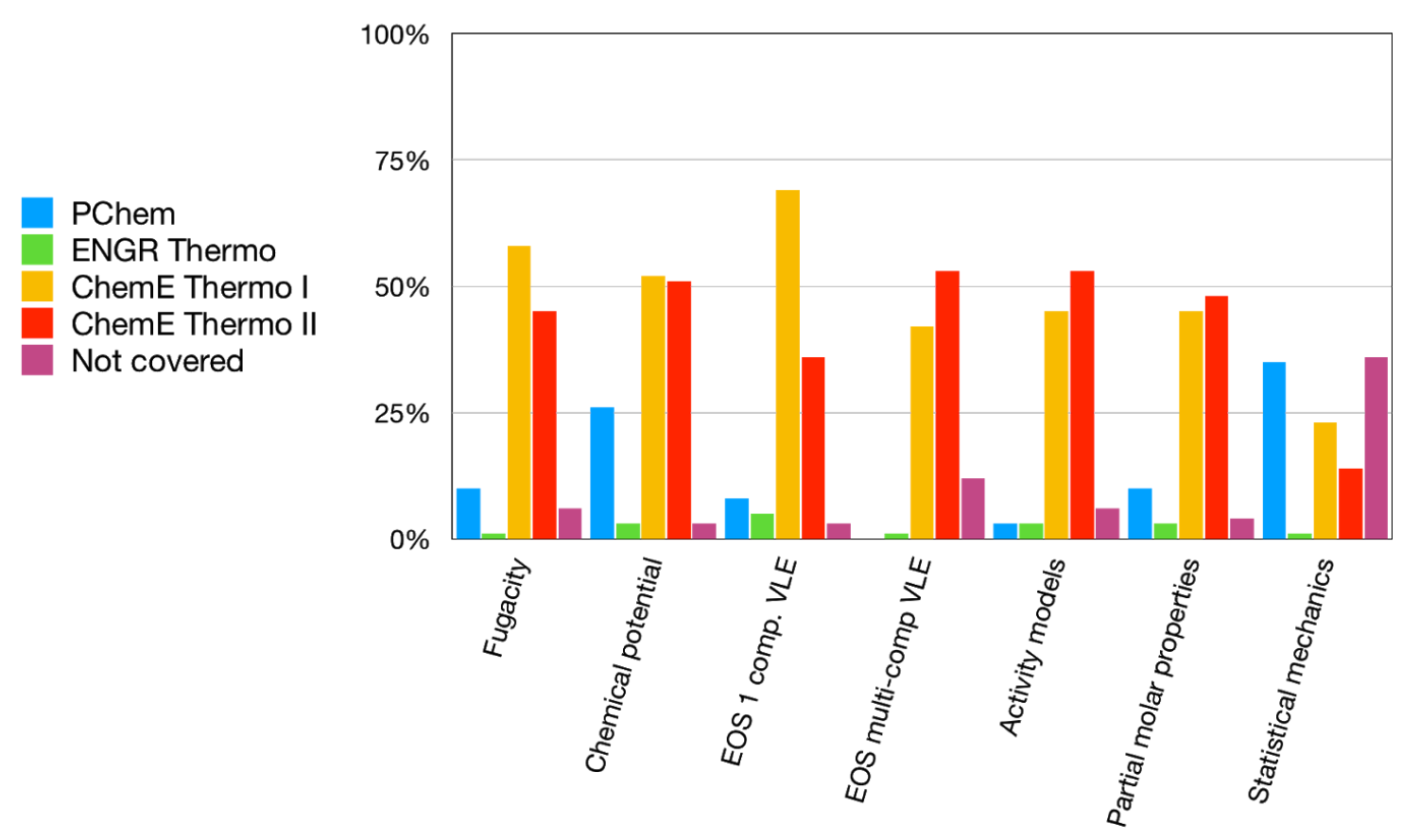

Figure 6: Molecular thermodynamics and models covered in courses. Topics may be reported to appear in multiple courses.

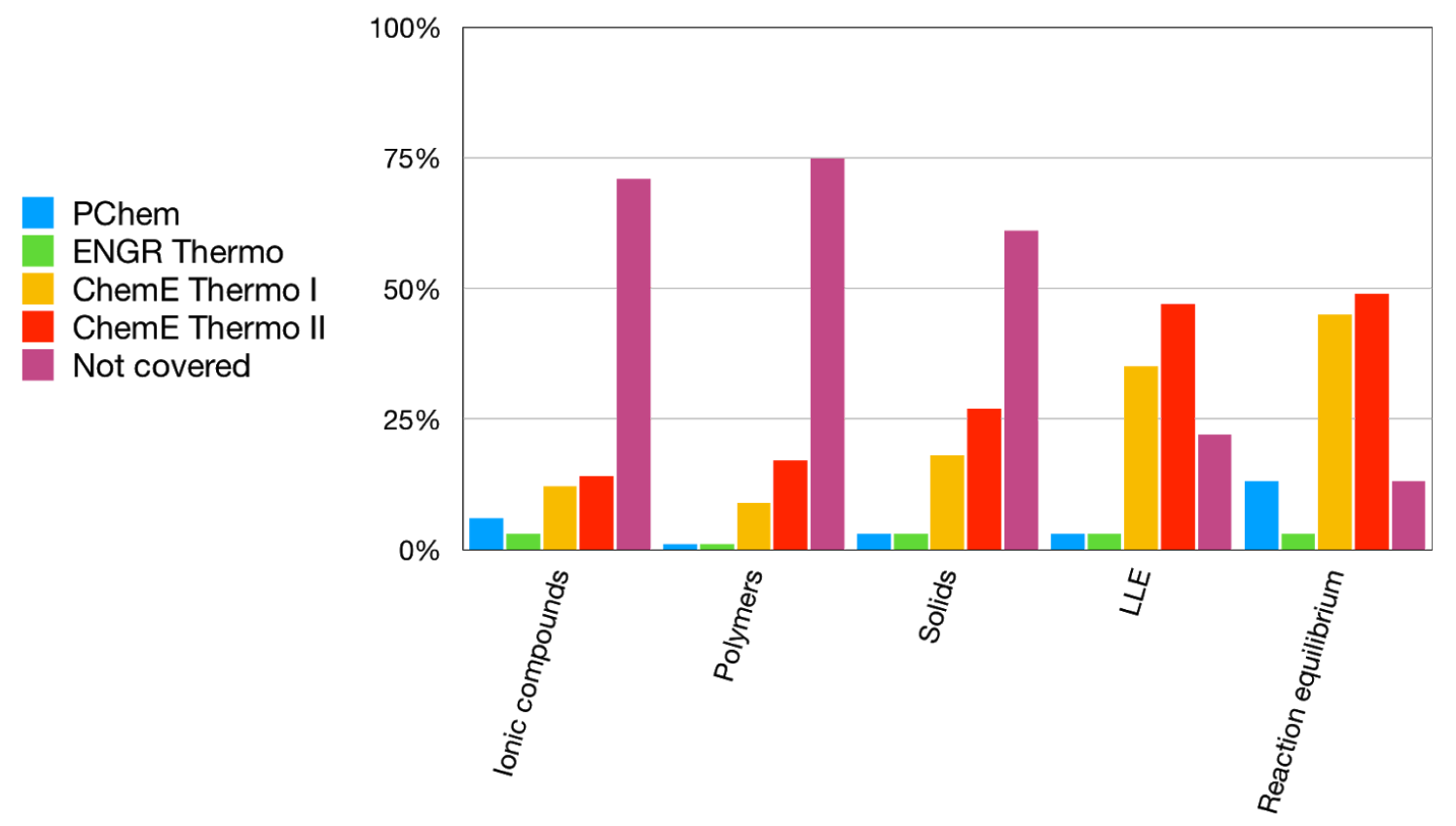

Figure 7: Equilibria and phase behavior coverage in courses. Topics may be reported to appear in multiple courses.

In addition to the topics discussed above, $26 \%$ of programs use the thermodynamics course as an opportunity to discuss process safety. These courses consider topics such as flash point, 
flammability limits, BLEVE, and pressure calculations for sealed vessels as part of their coursework.

As with many required courses, chemical engineering thermodynamics may be assessed for ABET outcomes in addition to technical content outcomes. Figure 8 shows the distribution of these assessments. ABET evaluation criteria covered within thermodynamics included a range of topics, including evaluation of information, environmental / political / scientific policies, writing and communications, and safety. In addition, 19 institutions focus solely on technical content within their course(s).

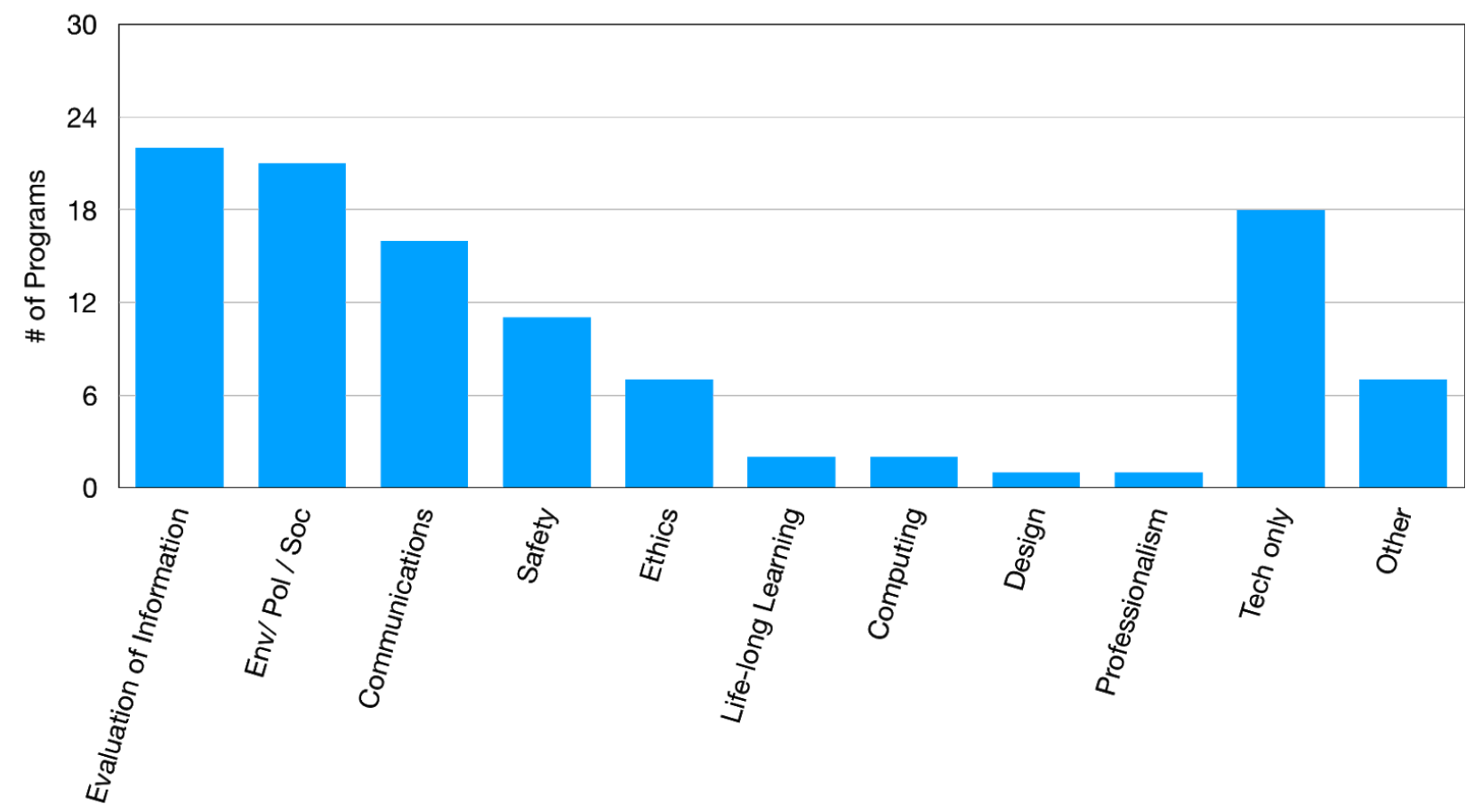

Figure 8: ABET outcomes assessed through chemical engineering thermodynamics.

Process and Setting

Unsurprisingly, all thermodynamics courses report using class / lecture time (Figure 9). Laboratories were only reported for two programs, explaining the small number of lab reports seen in Figure 10. 


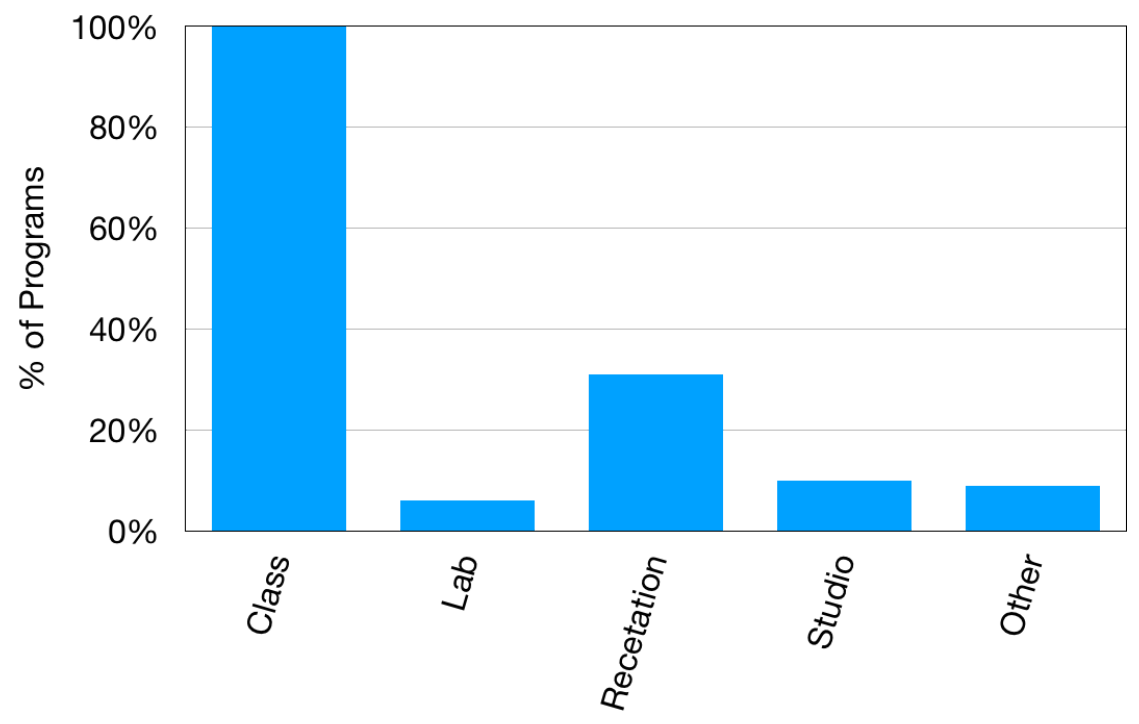

Figure 9: Types of instructional settings used by thermodynamics courses

In terms of assessment, all institutions use tests or exams for quantifiable analysis of student understanding. Problem sets are used by 82 of the 84 institutions; the two that did not instead specifically use quizzes and projects. Overall, quizzes were used by 56 institutions, concept questions were used by 55 institutions, and projects were used by 43 institutions.

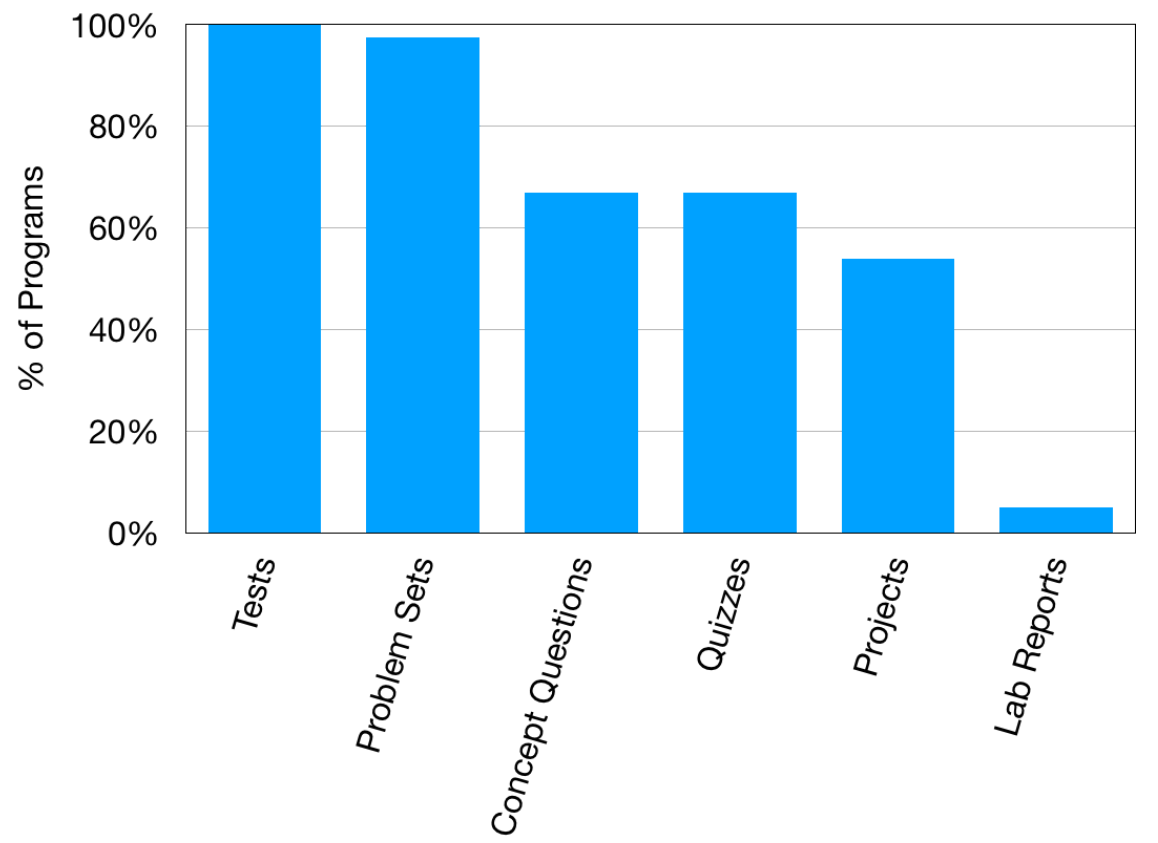

Figure 10: Types of assessments used in chemical engineering thermodynamics courses

This survey represents the first in the AIChE Education Division curriculum survey series where the majority of programs are reporting using concept questions (Figure 10). Concept questions are typically multiple choice questions, often used with instant response systems like "clickers", 
designed to assess student understanding of specific concepts within a knowledge space. More information on such questions along with many examples can be found at http://learncheme.com or http://cw.edudiv.org.

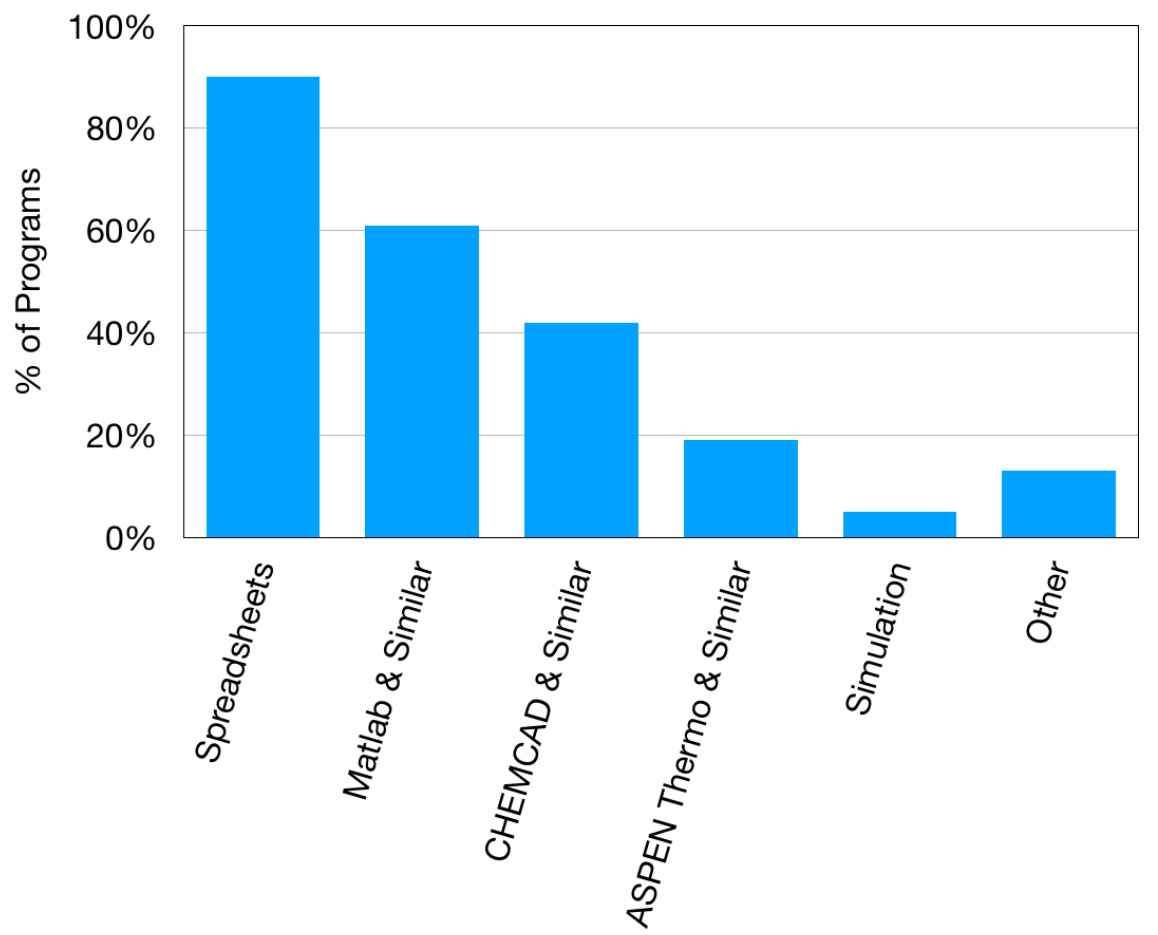

Figure 11: Computer use in thermodynamics classes

Computer usage, as shown in Figure 11, is nearly universal in thermodynamics courses. Survey responses indicate that these computational practices run the gamut from simple exercises in two-component phase equilibrium made easier by using a spreadsheet, through coding to generate PH or PV diagrams. Several programs report using thermodynamics courses as an opportunity to introduce process modeling software, such as Aspen, prior to capstone design.

When asked for innovative practices used in class, respondents replied with a suite of pedagogical ideas that might be applied in any course. Examples of these practices included motivating course material with relevant industrial processes, inclusion of environmentally-oriented applications, following a coaching (rather than lecturing) model for class, and design-based projects. Respondents also cited a variety of apps and online resources for thermodynamics help, concept problems, and ideas including LearnChemE.com, the AIChE Concept Warehouse, Piazza, and Kahoot. Some of the innovative practices were specific to thermodynamics and included having the entire class collaborate to develop a Txy diagram, having students build a Stirling engine, and solving the same problems with ideal gas, steam, and equations of state.

\section{Discussion}

Looking across the earlier AIChE surveys, we can see trends and consistencies in the timing of the course, the most popular textbook, and computer usage. Overall, from the 1970's-1990's 
thermodynamics tended to be taught to juniors in 3.0 credit hour courses with no laboratory. In 1973, the preponderance of schools taught thermodynamics using Smith and van Ness (1). By 1982, nearly two thirds of programs were requiring two thermodynamics courses, split between "engineering thermodynamics" and "chemical engineering thermodynamics" for $1 / 3$ of programs, or two chemical engineering courses for the remainder (3). Of the chemical engineering thermodynamics courses, $75 \%$ of them used Smith and van Ness as text (3).In the 1992 survey, $45 \%$ of programs were requiring two courses, and $66 \%$ were using Smith and van Ness, with Sandler appearing as the second-most popular at 22\% (4). Reported computer usage surged with the greater availability of personal computers in the $90 \mathrm{~s}$, up to $82 \%$ of programs (4). In the 2010 paper, just over $40 \%$ of US programs were requiring two courses (5). Textbook diversity in 2010 approaches the diversity seen in the present survey, with 39\% of programs using Smith, van Ness, and Abbott, 14\% using Elliott and Lira, and 13\% using Sandler (5). We see a trend towards greater diversity in textbooks, and towards moving thermodynamics earlier in the curriculum.

Starting in 1976 the survey questions begin to give insight into computer usage. In 1976, 47\% of programs report requiring at least one computer problem (2). Computer usage was significantly higher in 1982, where $37 \%$ of programs required at least $10 \%$ of the homework to be completed with a computer (3). Computers as a general tool now appear to be used in most assignments.

The 2010 survey goes into some depth about the topics taught in thermodynamics courses. Like the results above, they found that the central topics covered nearly universally include the first and second law, entropy, and phase equilibria (including vapor liquid equilibria) (5). Topics addressed by the plurality of programs include cycles, equations of state, and liquid-liquid equilibria - everything else is treated as either not-central or addressed by less than half of reporting programs in the US (5). In the older AIChE surveys, schools were not asked to provide an extensive list of topics, but were rather asked about which concepts were most difficult. These included entropy, fugacity, activity, partial molar properties, standard states, and solution thermodynamics, topics which have been lumped in the 2018 data as "molecular thermodynamics" and "models". The diversification of topics addressed in courses - both since the 2010 survey and overall - reflects the diversification of textbooks. There are fewer topics that we all agree are central to the course.

A preliminary version of the survey results were presented at the AIChE Annual Conference, and followed by a discussion about additional concerns related to teaching and learning in thermodynamics. The discussion is summarized in a Sketchnote (Figure 12). Proceeding from left to right across the image, the main discussion points included:

- That there are many more textbooks for thermodynamics than for other core courses. The group posited that this might be because we each have a preferred setting on the continuum from molecular to macro-scale, and pick a text to match.

- There is much more possible content for undergraduate thermodynamics than there are credit hours available, and so some cuts must be made. Most instructors present agreed that they were teaching fewer different power and refrigeration cycles than they had been taught, for example. 
- There is a lack of consensus on the proper order of concepts, including thermodynamics concepts covered in physical chemistry courses.

- The credit-hour pressure being exerted on public institutions to reduce the number of hours required for graduation is impacting thermodynamics courses (as well as others). Given this pressure, departments are trimming their hours in physical chemistry and thermodynamics, as can be seen in the move towards fewer courses relative to the 1990's survey.

- As shown in the survey, most thermodynamics instruction is still in-person, and not online.

- However, computer use in the course is common and includes chemical process modeling software.

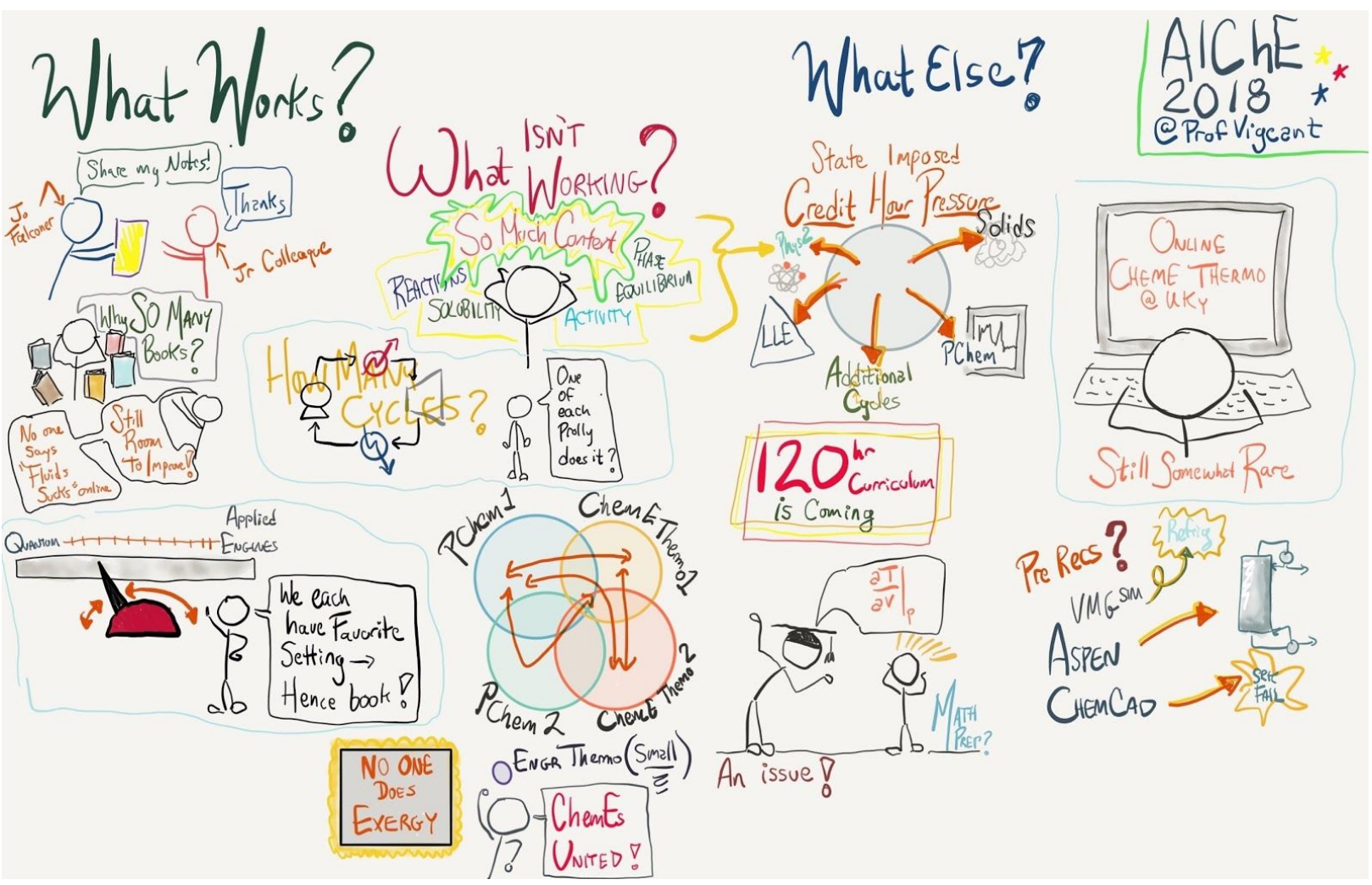

Figure 12: Sketchnote summarizing faculty discussion on thermodynamics instruction at AIChE Annual 2018.

\section{Conclusion}

The 2018 survey on how we teach thermodynamics communicated a significant diversity of instructional approaches, ranging from curricular variations in number and type of courses to the selection of topics within those courses. Pedagogical approaches appear to be transitioning, with conceptual questions rising notably in popularity. A mix of textbooks adoptions from both established and more recent authors combined with variation in course coverage suggest that there is still room for innovation in the thermodynamics instructional space. 


\section{Acknowledgements}

The authors would like to thank all of the department leaders who either responded to the survey or encouraged their faculty members to complete this survey, along with all of our respondents.

The authors would be happy to share electronic versions of the referenced reports (1-4) from the AIChE Special Projects Committee upon request.

\section{References}

1. E. Eisen, American Institute of Chemical Engineers National Conference (1973).

2. E. Eisen, D. Woods, A. Perna, American Institute of Chemical Engineers National Conference (1976).

3. E. Eisen, American Institute of Chemical Engineers National Conference (1982).

4. E. Eisen, A. Jones, American Institute of Chemical Engineers National Conference (1992).

5. P. Ahlstrom et al., Chemical Engineering Education 44, 35 (2010).

6. M. Vigeant, K. Dahm, D. Silverstein, American Association for Engineering Education (2017). 
Appendix: Survey Text Chemical Engineering Thermodynamics

Start of Block: Default Question Block

Q1.1 Thank you very much for responding to this survey. The AIChE Education Division Survey Committee asks member departments yearly about the current state of undergraduate education in a particular area of Chemical Engineering. This year, we are focusing on undergraduate thermodynamics.

We hope that this survey can be fully completed in 15 minutes or less by one member of the department who is familiar with the course offerings.

Previous recent surveys have been on Chemical Reaction Engineering, Thermodynamics, Design, Transport, Controls, Mass and Energy Balances, and the curriculum as a whole.

Questions? Please contact Margot Vigeant (committee chair) at mvigeant@bucknell.edu Thank you for your help!

Page Break

Q1.2 Departmental Characteristics

Q1.3 Name of your institution

Q1.4 Name of your department 
Q1.5 Number of faculty / instructors who teach in your department.

(please use this value as a snapshot of the number at the time this survey is completed; please include professors of practice, visitors, adjuncts, instructors, and tenured/tenure track in this value; please do not include graduate teaching assistants or research faculty.)

Q1.6 Does your department offer more than one undergraduate degree program?

(for example: Chemical Engineering and Biochemical Engineering)? NOTE - this is asking about degree title only, not minors, concentrations, or certificates. Most programs offer only one undergraduate degree.

Yes

No

Display This Question:

If Does your department offer more than one undergraduate degree program? (for example: Chemical Engin... = Yes

Q1.7 Name of the undergraduate degree program used as a basis for these answers

(note - this question is to accommodate departments offering multiple degree programs - such as Chemical Engineering and Materials Engineering - within one department. We recognize most programs only offer one degree. If your department offers multiple undergraduate degree programs, please consider re-answering this survey once for each of these programs). 
Q1.8 Considering the past three years, about how many undergraduates have graduated from your program per year, on average?

$\boldsymbol{\nabla} 1-20 \ldots$ More than 200 per year

Q1.9 Does your institution use quarters/ trimesters, semesters, or another system?

Quarters/ Trimester

Semester

Other

Q1.10

\section{Curricular and Course Mechanics}

On this page we have several questions about thermodynamics courses and how they work in your curriculum. When considering this question, please keep the following operational definitions in mind:

Physical Chemistry course: A course typically taught by the chemistry department. This course may have chemistry majors as the primary audience. Often, this is offered as a two-course sequence, where the chemical engineering majors take either one or both semesters.

General Thermodynamics course: A course typically taught within the engineering college/program. This course may be taught as a general engineering course and taken by many engineering majors, such as mechanical, civil, and chemical. This course often centers on the first and second laws and cycles.

Chemical Engineering Thermodynamics course: A course in thermodynamics typically taught within chemical engineering to a primary audience of chemical engineers. Such a course typically includes equations of state, activity models, and other approaches to modeling fluid behavior, as well as reaction thermodynamics. Most departments offer one or two required 
courses of this nature. While we will ask about the presence of the other courses in your curriculum, our topical questions areprimarily focused on courses of this type.

Q1.11 How many totalrequired courses in the Chemical Engineering undergraduate curriculum are Physical Chemistry or Thermodynamics courses?

$\boldsymbol{\nabla} 0 \ldots 13$ or more

Q1.12 Of the "Physical Chemistry or Thermodynamics" courses in the previous question, how many are "Physical Chemistry" courses, by the above definition?

$\nabla 0.3$ or more

Display This Question:

If Of the "Physical Chemistry or Thermodynamics" courses in the previous question, how many are "Phy... !=0

Q1.13 You indicated that students take at least one Physical Chemistry course. In the standard course sequence, when do students typically take the first/only Physical Chemistry course?

1st semester/ quarter 1 st year

2nd semester/ quarter 1st year

3 rd quarter 1 st year

1st semester/ quarter 2nd year

2nd semester/ quarter 2nd year

3rd quarter 2 nd year 
1st semester / quarter 3rd year

2nd semester/ quarter 3rd year

3rd quarter 3rd year

1st semester/ quarter 4 th year

2nd semester/ quarter 4th year

Other

Display This Question:

If Of the "Physical Chemistry or Thermodynamics" courses in the previous question, how many are "Phy... != 1

And Of the "Physical Chemistry or Thermodynamics" courses in the previous question, how many are "Phy... !=0

Q1.14 You selected that you have multiple Physical Chemistry courses in your curriculum. How are these courses related to each other?

They are Physical Chemistry 1 and Physical Chemistry 2

One is 'classical' Physical Chemistry, the other is Biological Physical Chemistry

Other. Explain:

Q77

Curricular and Course Mechanics 
On this page we have several questions about thermodynamics courses and how they work in your curriculum. When considering this question, please keep the following operational definitions in mind:

Physical Chemistry course: A course typically taught by the chemistry department. This course may have chemistry majors as the primary audience. Often, this is offered as a two-course sequence, where the chemical engineering majors take either one or both semesters.

General Thermodynamics course: A course typically taught within the engineering college/program. This course may be taught as a general engineering course and taken by many engineering majors, such as mechanical, civil, and chemical. This course often centers on the first and second laws and cycles.

Chemical Engineering Thermodynamics course: A course in thermodynamics typically taught within chemical engineering to a primary audience of chemical engineers. Such a course typically includes equations of state, activity models, and other approaches to modeling fluid behavior, as well as reaction thermodynamics. Most departments offer one or two required courses of this nature. While we will ask about the presence of the other courses in your curriculum, our topical questions areprimarily focused on courses of this type.

Q1.15 Of the \$\{1.11/ChoiceGroup/SelectedChoices $\}$ "Physical Chemistry or Thermodynamics" courses that you indicated your students take above, how many are "Thermodynamics" courses (either General or Chemical Engineering), by the above definitions?

$\nabla 0 \ldots 5$ or more

Display This Question:

If Of the $\$\{\mathrm{q}: / / \mathrm{QID} 70 /$ ChoiceGroup/SelectedChoices $\}$ "Physical Chemistry or Thermodynamics" courses th... !=0

Q1.16 You indicated that students take at least one Thermodynamics course. In the standard course sequence, when do students typically take the first/only Thermodynamics course?

1 st semester / quarter 1st year

2nd semester / quarter 1st year 
3rd quarter 1st year

1st semester / quarter 2nd year

2nd semester / quarte r2nd year

3 rd quarter 2 nd year

1st semester/ quarter 3rd year

2nd semester / quarter 3rd year

3rd quarter 3rd year

1 st semester/ quarter 4 th year

2nd semester/ quarter 4th year

Other

\section{Display This Question:}

If Of the $\$\{\mathrm{q}: / / \mathrm{Q} I D 70 /$ ChoiceGroup/SelectedChoices $\}$ "Physical Chemistry or Thermodynamics" courses th... $=2$

Q1.17 You indicated that students take a second Thermodynamics course. In the standard course sequence, when do students typically take this second Thermodynamics course?

1st semester / quarter 1st year

2nd semester / quarter 1st year 
3rd quarter 1st year

1st semester / quarter 2nd year

2nd semester / quarte r2nd year

3 rd quarter 2 nd year

1st semester/ quarter 3rd year

2nd semester / quarter 3rd year

3rd quarter 3rd year

1 st semester/ quarter 4 th year

2nd semester/ quarter 4th year

Other

\section{Display This Question:}

If Of the $\$\{\mathrm{q}: / / \mathrm{Q} I D 70 /$ ChoiceGroup/SelectedChoices $\}$ "Physical Chemistry or Thermodynamics" courses th... $=1$

Q1.18 You indicated that students take one "Thermodynamics" course. Please tell us a little more about this course:

It is an Engineering Thermodynamics course (as defined above)

It is a Chemical Engineering Thermodynamics course (as defined above) 
Other

Display This Question:

If Of the $\$$ \{q:/QID70/ChoiceGroup/SelectedChoices $\}$ "Physical Chemistry or Thermodynamics" courses th... != 1

And Of the "Physical Chemistry or Thermodynamics" courses in the previous question, how many are "Phy... !=0

Q1.19 You selected that you have multiple Thermodynamics courses in your curriculum. How are these courses related to each other?

Students take General Engineering Thermodynamics and then Chemical Engineering Thermodynamics

Within Chemical Engineering, we teach Thermodynamics 1 and Thermodynamics 2

Other. Explain:

Q1.20 What is the typical (last 5 years) class size in your Chemical Engineering thermodynamics course(s)? (Please answer for Engineering Thermodynamics course if that is the only one taken).

Q1.21 How many sections of your Chemical Engineering Thermodynamics course(s) are typically offered per academic year? (Please answer for Engineering Thermodynamics course if that is the only one taken).

$\nabla 1 \ldots 7$ or more 
Q1.22 How many credit hours (or equivalent) does your Chemical Engineering Thermodynamics course(s) receive? (Please answer for Engineering Thermodynamics course if that is the only one taken).

Q1.23 Check the box for each element that is part of your course and tell us how many hours each week are devoted to each of the following for your Chemical Engineering Thermodynamics course(s) (Please answer for Engineering Thermodynamics course if that is the only one taken):

Classroom instruction

Laboratory

Recitation

Studio

Other

Display This Question:

If Check the box for each element that is part of your course and tell us how many hours each week a... = Laboratory

Q1.24 You said that your thermodynamics course(s) has a laboratory. Is this laboratory:

Primarily experimental, using physical apparatus

Primarily modeling / simulation / virtual experiments

A mix of computer and physical experiments 
Q1.25 Is process safety part of any of your thermodynamics courses?

Yes

Maybe

No

Display This Question:

If Is process safety part of any of your thermodynamics courses? != No

Q1.26 You said process safety is or might be part of one of your thermodynamics courses. How is it addressed?

Page Break

End of Block: Default Question Block

Start of Block: Goals and Technical

Q2.1 For Engineering Thermodynamics and Chemical Engineering Thermodynamics, which textbook(s) are used? Select and write in all that apply

Atkins \& de Paula

Baehr 
Borgnakke \& Sonntag

Cengel, Boles, \& Kanoglu

Dahm \& Visco

Elliot \& Lira

Felder, Rousseau, and Bullard

Gmehling

Halder

Kolbe

Koretsky

Matsoukas

Moran, Shapiro, Boettner, \& Bailey

Narayanan

Prausnitz

Sandler 
Smith, van Ness, Abbott, \& Swihart

Other(s)

Q2.2 In which format(s) are students accessing and interacting with their textbook(s)? Select all that apply.

Physical paper book

e-book purchased from university bookstore / publisher

Non-editable e-book accessed as an open educational resource (free)

Editable e-book created by students, either in-whole or in-part

Other

Q2.3 What ABET (aside from technical competence) and/or university level outcomes are assessed within this course? Select all that apply.

Writing / communications

Safety

Ethics 
Regulatory understanding/compliance

Knowledge of environmental / political / social impacts

Evaluation of information sources

Other

Q2.4 What deliverables are typically part of your Chemical Engineering Thermodynamics course(s)? Select all that apply.

Problem sets

Concept questions (with or without electronic "clickers")

Quizzes

Tests / Exams

Lab reports

Projects

Other

Display This Question: 
If What deliverables are typically part of your Chemical Engineering Thermodynamics course(s)? Selec... = Projects

Q2.5 You selected that "projects" are part of your Chemical Engineering Thermodynamics course. Please tell us a little about the project's goals, duration, or anything else interesting about it. Please also let us know if you use multiple projects.

Q2.6 Below are some of the concepts and content often found within the thermodynamics sequence. Please check the course in which each topic is addressed. If one of the courses listed is not taken by your students, please leave that column blank.

If only one chemical engineering thermodynamics course is taken, please use the column for "chemical engineering thermodynamics 1 " to designate.

In the topics below, vapor-liquid equilibrium is abbreviated "VLE".

Note we recognize not every possible course outcome is captured here, so please use the "other" selection to tell us about the other things you include.

\begin{tabular}{|c|c|c|c|}
\hline Addressed & Addressed in & Addressed in & Addressed in \\
\hline in required & & & \\
\hline Physical & Thermodynamics & Engineering & Engineering \\
\hline Chemistry & & Thermodynamics & Thermodynamics \\
\hline & & (or Chemical & 2 \\
\hline & & Engineering & \\
\hline & & Thermodynamics & \\
\hline
\end{tabular}

1)

First law

Second law 


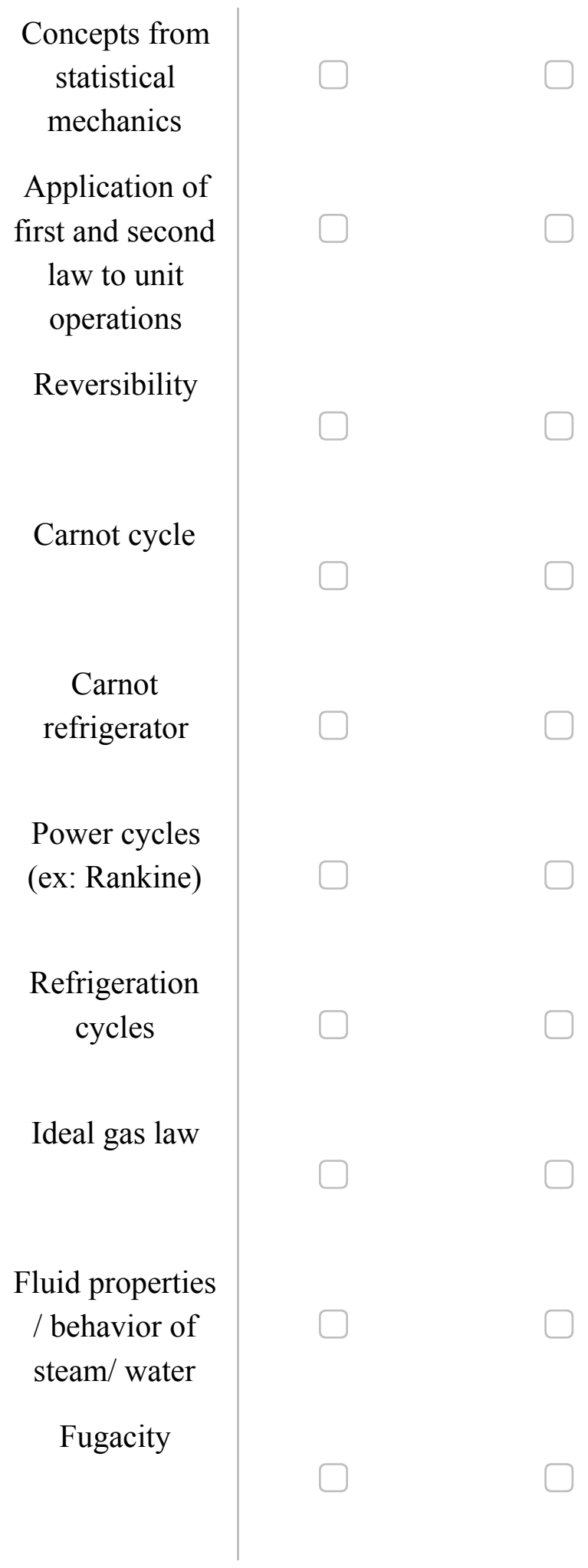




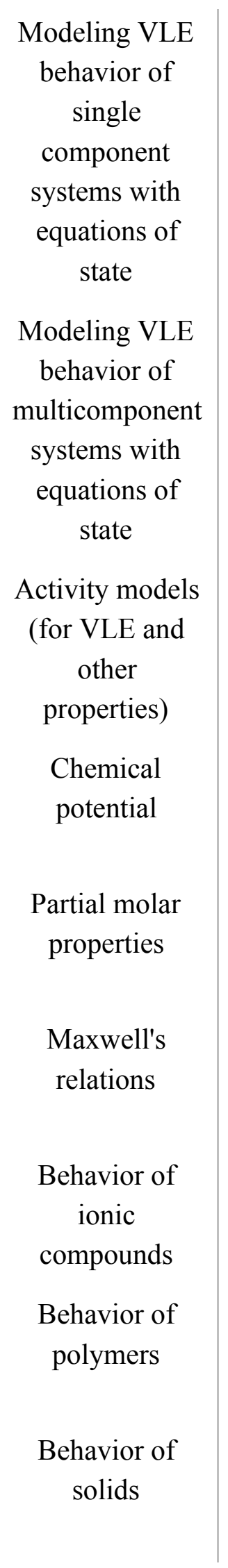




Liquid / Liquid
equilibrium
Reaction
equilibrium
Other (please
elaborate
below)

\section{Display This Question:}

If Below are some of the concepts and content often found within the thermodynamics sequence. Pleas... [ Other (please elaborate below)] (Recode) Is Not Empty

Q2.7 You selected "other" in the question on topics above. What other topics do you address in class?

Display This Question:

If Below are some of the concepts and content often found within the thermodynamics sequence. Pleas... [ Power cycles (ex: Rankine)] (Recode) Is Not Empty

Or Below are some of the concepts and content often found within the thermodynamics sequence. Pleas... [ Refrigeration cycles ] (Recode) Is Not Empty

Q76 You selected that your courses include power and/or refrigeration cycles. Which specific cycles are typically covered? 
Q2.8 Which is the best description of when students engage with "energy balances" in your curriculum?

Energy balances are significantly covered in another required course that is prerequisite for the aforementioned thermodynamics courses, and are reviewed or treated as "previously learned material" during thermodynamics courses.

Energy balances are first introduced in another required course that is prerequisite for the aforementioned thermodynamics courses, but are covered in depth in the aforementioned thermodynamics courses.

Energy balances are, for typical students in our program, introduced for the first time in the aforementioned thermodynamics courses.

Other

Q2.9 Do students use computers for computational problem solving or modeling in this course?

Yes

Maybe

No

Display This Question:

If Do students use computers for computational problem solving or modeling in this course? $!=$ No

Q2.10 You said that students use (or might use) computers in your course(s). What software are they using? (select all that apply). 
Process modeling software (ex: CHEMCAD, Aspen)

Phase and chemical property modeling software (ex: Aspen Hysys COM Thermo)

Spreadsheets (ex: Excel)

Calculation and programming environments (ex: Matlab)

Simulation (ex: PhET simulations)

Other

Q2.11 We are always looking for innovative practices in core chemical engineering courses. Are there any teaching approaches, assignments, assessments, or other practices that are a highlight of your Thermodynamics course(s)?

End of Block: Goals and Technical

Start of Block: Conclusion Block

Q3.1

\section{Conclusion}

We thank you for your participation! This helps all of us better understand the state-of-the-art in chemical engineering education. 
Q3.2 We may have a more detailed follow-up questionnaire on certain programs. Would you be willing to be contacted for this follow-up?

Yes

No

Q3.3 We will be compiling the results of this survey for distribution at the AIChE annual meeting and the ASEE annual meeting. If you would like us to send you a copy of the processed results, please put your email address below. We may also use that email to make a follow-up appointment if you select "yes" above.

End of Block: Conclusion Block 